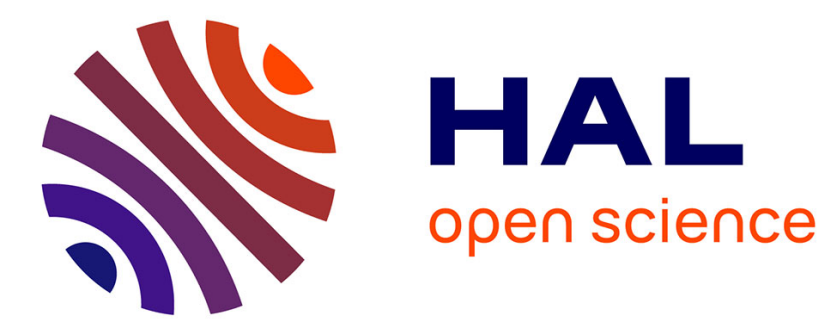

\title{
Fiction, Indispensability and Truths
}

\author{
Manuel Rebuschi, Marion Renauld
}

\section{To cite this version:}

Manuel Rebuschi, Marion Renauld. Fiction, Indispensability and Truths. Truth in Fiction, Ontos Verlag, pp.245-286, 2011. halshs-00556265

\section{HAL Id: halshs-00556265 https://shs.hal.science/halshs-00556265}

Submitted on 16 Jan 2011

HAL is a multi-disciplinary open access archive for the deposit and dissemination of scientific research documents, whether they are published or not. The documents may come from teaching and research institutions in France or abroad, or from public or private research centers.
L'archive ouverte pluridisciplinaire HAL, est destinée au dépôt et à la diffusion de documents scientifiques de niveau recherche, publiés ou non, émanant des établissements d'enseignement et de recherche français ou étrangers, des laboratoires publics ou privés.

\section{(1)(1) $\$(0)$}

Distributed under a Creative Commons Attribution - NonCommercial - ShareAlikel 4.0 


\title{
Fiction, Indispensability and Truths
}

\author{
Manuel Rebuschi \& Marion Renauld \\ (Nancy University, Poincaré Archives, UMR 7117)
}

March 15, 2010

[Final version in F. Lihoreau (ed.), Truth in Fiction, Ontos Verlag (2010), 245-286.]

\begin{abstract}
Based on a modification of the indispensability argument, the paper claims that fictions are indispensable, thus true, and simultaneously rejects any ontological commitment to fictional entities. In the first part, data coming from natural language semantics are gathered to argue for a disconnection between truth and ontology, against Quine's criterion of ontological com mitment. In the second part, we exploit analyses from literary criticism and philosophy of art to support the indispensability of fiction, and to account for a strong sense of truth of fiction. In the background of the paper lies the idea that fictional narrations pertain to the interpretative and practical uses rather than to any descriptive use of language.
\end{abstract}

\section{Introduction}

The indispensability of mathematics thesis of Quine and Putnam, implicitly involving Quine's ontological commitment criterion, leads us to accom modate mathematical entities within our ontology. Such a com bination of the thesis (of indispensability) and the criterion (of commitment) appears to be a prevalent paradi gm in analytic philosophy, as far as one is concerned with ontological issues. The specific case of fictional narrations is consequently promptly shrugged off: since they are not indi spensable, such narrations cannot be true (an idea already present in Frege), hence they do not commit us to anything. The purpose of the paper is to show that the com bination of the thesis and the criterion is not transposable to fiction in a straightforward way. To em brace fictional narration, one needs to distinguish between two moments, admit of a kind of indispensability, thus a kind of truth in the fiction, while rejecting ontological commitment regarding fictional entities.

Our argument in not ad hoc, tailor-m ade for fiction. It is grounded in a criticism of the narrowness of the context of application of Quine's com bination. Following Frege, Quine indeed restricts his logical analysis to som e very specific use of language: that of scientific knowledge, if not theorized know ledge, of the world. Moreover, both authors agree that natural language (hereafter NL) is not a good $\mathrm{m}$ edia to express our theories, and that we should either go through a Begriffsschrift freed from vernacular languages' am biguities (Frege), or translate (or "regim ent") our theoretical sentences into the canonical language offered by first-order logic (Quine).

It is quite obvious that uses of language are not restricted to the only cases of theoretic or scientific sentences, and more generally that they are confined neither to the expression of our knowledge, nor to that of descriptions of the wo rld. Far from formalized theories, we are also involved in the practical game of multiple interpretations of the world and of our fellow creatures, and these interpretations do not seem reducible to $\mathrm{m}$ ore or less naturalized descriptions. Here we follow a traditional distinction between explication and comprehension, i.e. between the positive $m$ ethod of natural $\mathrm{sc}$ iences and the herm eneutic method of moral sciences (see Descombes 1995: 51). The contrast is indeed endorsed by Quine him self with the principle of a "double standard" (Quine 1960: § 45), i.e. of a sharp separation between what is knowable (which can be theorized, natura lized, etc.) and intentional issues (which are practically manageable, but where there is nothing to be known). 
Indispensability, which is a good path to reach truth, need not be reserved for the only descriptive, epistemic and theoretical uses language. We will propose to expand it to every discourse involved in our understanding or comprehension of the world, indeed in our practical apprehension of the world (if it is extended to non linguistic know-how). W e propose to characterize as true the discourses wh ich are indispensable to our apprehension of the world, including the non-theoretical one. In orde $r$ to avoid the threat of relativism - truth being defined by utility not only in our descriptions but also in our interpretations - we draw our inspiration from Dennett (1987) whose purpose is to build bridges between interpretation and description, over the double standard gap: a criterion of usefulness enables him to involve intentionality into our theoretical explan ations, although it is on the "dark side" for knowledge.

Furthermore, far from any canonical and id eal language, we are all involved in $\mathrm{m}$ any practices of natural language where som e of the a ssumptions of formal languages are merely removed. The strong connection drawn up between bound variable and ontological commitment appears to be dependent on the som ewhat ethereal atm osphere of first-order logical languages. The well-known criticism of Russell's theory of descriptions (1905) by Strawson (1950) is one of the rem arkable manifestations of the im portance of pragm atic features in linguistic understanding, whereas these features are completely absent from formal languages. Since then, NL semanticists had to include numerous phenomena related to the use of language in context. The upshot is a picture of language (as it is spoken) that is far richer than the picture Quine relied on to shape his ontological commitment criterion. We propose to embrace that richness, and to give up the criterion.

Our strategy is as follows. We want to disent angle two aspects of Quine's indispensability argument, which appear to be $\mathrm{m}$ utually independent. First, there is an entailm ent from indispensability to truth: if some (theoretical) discourse - like mathematics - is indispensable for our holistic explanation of the world, then it must be acknowledged as true. Second, there is an im plication between truth and ontology : this is Quine's criterion of ontological commitment. We will claim that one should ge neralize the relation between indispensability and truth, and also cut the link between tr uth and ontology. The resulting position regarding fiction will be that one can acknowledge truth in fiction, but with no ontological com mitment to fictional entities.

The argument of the paper is a two-step one. First we will argue negatively against the universality of Quine's ontological com mitment criterion, i.e. for an interpretation of NL quantification (and more generally, of NL semantics) as ontologically neutral. This part is not specifically linked to fictional discourse sin ce it is intended to account for the way language works in general. The idea is that at an inte rpretation level, one can handle quantifiers, proper names, and even truth, without prejudice to what happens at an external level. In a second part, we will argue positively in favor of indisp ensability, hence truth in a strong sense, for fictional discourse. The issue will thus be to shed light on the kind of truth that can be involved in some non-descriptive use of language.

\section{PART 1. TRUTH WITH NO ONTOLOGICAL COMMITMENT}

In this part, we will argue against Quine's criterion of ontological commitment. We will claim that it is linked to som e partial view of language, and that it should not be applied as such in more general cases, especially to fictiona 1 discourse. Actually, such a criterion seem $\mathrm{s}$ appropriate for very idealized situations, where the context of use does not play any role and the utterances can be interpreted using only se mantic vs. pragmatic resources. To put it in other words: as far as context is out of play, Quine's criterion might be in - and vice versa. 
In the background, we have to stress the c ontrast between two $\mathrm{m}$ ajor conceptions of semantics: (i) a representational conception, according to which semantic theories account for the relations between language and reality, and (ii) a procedural view, according to which semantics should provide explanations of the language users' understanding of the meaning of sentences and discourses. We will show that Qu ine's conception is of the first kind, whereas natural language sem anticists often shift to conceptions of the second kind. This shift is expected to yield im portant consequences about the purported connection between sem antics and ontology.

\section{The universalistic tradition}

The representational view of sem antics clearly dominates the origins of logical analysis. Actually, Frege's apprehension of sem antics and Russell's are com parable in that, whatever specific theory is considered the best one, sem antic correlates of at least singular expressions automatically carry som e ontology about them . And according to $\mathrm{m}$ any followers and commentators, after accurate regimentation not only singular terms, but also every expression of language, trigger an ontological com mitment. In this received view, Frege and Russell seem to have admitted semantic correlates of general terms (concepts and senses of concepts, or Universals), and of sentences (truth-value s and thoughts, or Propositions), as ontologically relevant in the same manner as singular terms. Consequently, ontology exactly maps language as semantically theorized (and reciprocally): when semantics is dualistic, such as Frege's, the world splits into (at least) two parts (an intensional part and an extensional one); ${ }^{1}$ if it is monistic, such as Russell's, one world is sufficient.

This "ontologizing" understanding of semantics, which seems to have been shared by many after Frege and Russell if not by them selves, entails $m$ eta-theoretical choices throughout language analysis, e.g. the particularly intri cate treatment of empty singular terms by Frege who wanted to avoid any com mitment to fictional entities. Russell's drastic reduction of the category of genuine singular term s, though connected to epistemic features, follows the same tack, as do contemporary "neo-Russellian" criticisms of the legitimacy of individual concepts.

At odds with Frege and Russell, Quine explicitly restricts ontological com mitment to one syntactic category, namely variables. This is his well-known criterion:

"To be is to be the value of a variable" (Quine 1948)

Quine's strategy enables one to use predicat es and to assert sentences without being committed to platonic objects such as Universa ls or Propositions; therefore, Quine's account may look somewhat like nominalism, although it is still full-fledged realism about particulars. Thanks to Quine's accordance with universalism , ${ }^{2}$ such syntactically delim ited ontology is still conceived of as genuine ontology: as there is one language - first-order logic being the canonical language of regim entation of science - and one world - see Quine's disinterest in model-theory, or his rejection of $\mathrm{m}$ odal logic -, language is always related to reality. The restriction of ontological com mitment to variab les thus does not im ply any shift from the classical view of semantics as representational.

\footnotetext{
1 Each part $\mathrm{m}$ ay split again according to syntactic cate gories (singular term $\mathrm{s}$, general terms, sentences). Moreover, Frege's ont ology adds another world, corresponding to the connotative or "subjective" aspects of language (which are not accounted for by its semantics).

2 See van Heijenoort (1967) and Hintikka (1988) for th e distinction between two traditions in logic: the universalistic tradition and the model-theoretic tradition, respectively involving two rival views about language: language-as-medium vs. language-as-calculus.
} 
After the so-called "linguistic turn" in ph ilosophy, Quine's conception of ontology and of (extensional) semantics became the m ost prominent framework for different fam ilies of metaphysical realists, who consider som e or all of the sem antic items as bona fide, i.e. ontologically relevant, objects. ${ }^{3}$ Moreover, technical issues with in logical semantics such as the status of individual concepts are ge nerally challenged while presupposing Quine's criterion. It should yet be noticed that Quine never claim ed to account for linguistic meaning, a notion he held to be suspicious, and that his regimentation explicitly parts $\mathrm{f}$ rom sensepreservation or synonymy (Quine 1960, §33).

Quine's support for universalistic ideas actually entails a strong connection between logic and ontology, whereas the implicated meta-theoretical constraints seem to have forced him to depart from a complete explication of natural language semantics (and from a great part of the technical logic developments). The universalistic conception of semantics thus appears to be strongly normative, since what there (presumably) is intervenes as a coercion through language analysis, and leads to revisionist strategies. To put it in a nutshell: Quine's conception implies that ontological considerations come first, and that sem antic theories (an particularly procedural semantics) should adapt or die.

\section{The model-theoretic turn}

Tarski opened new perspectives in and on semantics. His system atic meta-theoretical approach to sem antics entails, by itself, the possibility of language-shifts; going further, model theory allows world-shifts, i.e. reinterpretations of language. The expansion of Quine's criterion to the new model-theoretic frame leads one to identify ontology with the dom ain of an interpretation structure of a form alized language. Such identification $\mathrm{m}$ ay be labeled as Model-Realism (hereafter, MR). Though inherited from universalism, MR seem s to be the dominant position since Tarski's sem antic turn; according to this view, sem antics should consist of (or depend on) representational theories.

Let us call that language-and-sem antics-relative "ontology" - i.e. the constituents of the domain(s) of a structure - the Technical Semantic Ontology (hereafter, TSO). Does it m ake sense to think of TSO as genuine ontology, i.e. as what there is $?^{4}$ It seems intuitively that if one expects it to $\mathrm{m}$ ake sense, one needs to choose a single language and a single semantic interpretation of that language as the best ones. ${ }^{5}$ In other words, TSO seem s to be genuine ontology... if we choose to go back to universalism.

At first glance, Tarski-type sem antics could explain the genuine relation holding between (some) language and (som e) world. It looks as if it could explain truth as a correspondence between language and world (regim ented as an interpretation structure). It $\mathrm{m}$ ay - and did consequently reinforce the "ontologizing" conception of sem antics advocated by Quine's criterion.

At the same time, Tarski-type sem antics allows natural and straightforward solutions for issues raised within Fregean and Russellian sem antics, such as the problem of empty singular terms. For instance, in order to provide a truth-functional sem antics for fiction, one can easily quantify over a dom ain of fictional objects; whether one favors direct-referential vs.

\footnotetext{
${ }^{3}$ Many contemporary logical accounts of the semantics of fiction do not cut off from this general conception. See Gochet (2010) for a brief overview.

${ }^{4}$ In Carnap's words (1950), the issue is to know whether internal questions of existence should be identified with external questions.

${ }^{5}$ In the same way for instance that Quine avoids semantic variability: he roughly rules out possible (non-actual) worlds, and chooses the holistic language of science.
} 
descriptivist theories, the very sam e domain can provide (fictional) "referents" for (fictional) proper names conceived as rigid designators. Does such a tolerance im ply any ontological commitment to fictional entities? If Quine's crite rion is to be carried over to $\mathrm{m}$ odel theory, TSO (here "fictional objects") will then cons titute a genuine ontology. Sem anticists should consequently either assume some very liberal and luxuriant ontology - taking fictional entities at face value -, or attem pt to avoid this co mmitment by some theoretical revision. The sam e goes for possible-worlds sem antics according to whether one is willing to com mit oneself to "possible objects" or not.

Ontology-oriented or representational sem antics again appears to im pose strong constraints on theories. It is embodied in the meta-theoretical choice to split usual singular terms into two categories in line with ontology. ${ }^{6}$ In spite of (possible) appearances, a descriptivist Russelllike understanding of usual proper nam es is no exception to the rule: if a definite description is vacuous and occupies a subject position, the whole sentence is system atically false and therefore entails lots of unintended consequences.

Such a com plication of sem antic theories is already questionable. W e also think it is illegitimate. A strong argum ent in favor of non- committing semantics - i.e. against MR - is the theoretical uniformity it allows. ${ }^{7}$ It is not sufficient by itself but can be warranted on methodological grounds, as follows.

In his criticism s of Donnellan's sem inal paper about descriptive and referential uses of descriptions, Kripke (1977) argues for "unitary theories" against "theories that postulate [semantic] ambiguity", if the alleged am biguity is not expected "to be disam biguated by separate and unrelated words in som e other language"; so, against Donnellan's (1966) conception of semantic values shifting with uses of description, Kripke favors an account "on pragmatic grounds, encapsulated in the distincti on between speaker's reference and sem antic reference" (op.cit.: 3c).

While splitting usual singular term $\mathrm{s}$ into tw o classes according to (som e presumed) ontology, Model-Realists postulate a kind of (superfluous) linguistic am biguity: semantic values of expressions are supposed to shift with $\mathrm{m}$ utations in presumed ontology. For example, the same usual proper nam e "Santa Claus", as used by a believing child or by his skeptical parents, would have different semantic interpretations. ${ }^{8}$

As far as sem antic theories are concerned with linguistic meaning, it is quite am azing to postulate shifts of values with changes of (ontological) beliefs. ${ }^{9}$ In $\mathrm{f}$ act, the distinction between these two uses cannot be adequately captured by Tarski-type sem antics. What happens, for instance, when the parents and their child speak together of "Santa Claus"? How can non-believers refer to a non-existent? Of course they cannot: they can only pretend to refer. But if they want to teach the $m$ yth as a true story they can, and even need to share their

\footnotetext{
${ }^{6}$ The boundary between those two categories may fluctuate from one philosopher to another. An extreme case is that of the advocates of genuine "non-existent objects": they reduce the class of genui nely vacuous singular terms to the empty class.

${ }^{7}$ As a proponent of a maximally liberal ontology, Zalta rightly insists on this point: "Once we are able to see that all significant proper names are names of object $s$, we m ay simplify the Tarski-style definition of $t$ ruth for languages in which names of nonexistents appear along with nam es of exis tents. The truth conditions $\mathrm{m}$ ay be specified more systematically, since no special precautions need to be take $\mathrm{n}$ to distinguish the two kinds of names". (Zalta 1984: 2) (In return, his support for MR forces him to acc ount for a general "m etaphysics of object", including nonexistents.)

${ }^{8}$ Moreover, MR leads to the counterin tuitive upshot that histori cal discoveries - e.g. som e confirmation of the conjecture that Homer never existed - amount to some semantic change.

${ }^{9}$ This contradicts our pre-theoretical notion of linguistic meaning; cf. Evans (1982: 23-24).
} 
child's belief object, namely the semantic value he or she assigns to the $m$ ythical name. In other word, whenever veraciously speaking about "Santa Claus", in a fictional or serious manner, one needs to postulate a genuine semantic (if not ontological) correlate for that name. Fictionally or seriously (believed) uses of singular term $\mathrm{s}$ and their related speech acts, pretended or genuine reference, need not and cannot penetrate into sem antics. As Recanati puts it, "the difference does not $\mathrm{m}$ atter from a strictly linguistic point of view. For we use the same linguistic material, with the sam e linguistic meaning, whether we genuinely refer or only pretend to refer. This follows from the very notion of 'pretense'." (1996: 467).

Incidentally, our criticism of the standard processing of empty proper nam es expands to usual theories $f$ or the sem antics of fiction: ${ }^{10}$ free logics (Lam bert 2003) as well as substitutional accounts of quantification (Kripke 1976) rely on the a priori and ad hoc definition of a class of specific proper nam es (constants to which no existential generalization apply for free logics, substitutional terms for substitutional quantification), that entails a loss of uniformity in the semantic analysis of proper names.

\section{Beyond (first-order) formalized languages}

Where does model-realism come from? It seems to be straightforwardly im plied by a strict application of Quine's ontological com mitment criterion to $\mathrm{m}$ odel-theory: if a sentence consists in an existentially quantif ied formula true in a given structure, then the value of the quantified variable $m$ aking the sentence tr ue must be acknowledged into the ontology. However, such an application lacks a justif ication. Should one take it for granted that quantifiers behave the sam e way in every possi ble context where m odel-theory applies? It appears not to be the case. Like Frege, Quine stic ks to some very restrictive class of uses of language: that of genuine descriptive se ntences, and his criterion depends on the regimentation of such sentences into an adequate logical language. $\quad{ }^{11}$ Of course, $m$ any language-games do not fit with Quine's favorite one.

\subsection{Taking context into account}

Strawson (1950) challenged Russell's (1905) standard analysis of descriptions. In the norm al use of definite description we generally invoke incomplete descriptions, like "the table", and so we achieve referring to individual objects. However, there is not a unique table in the universe, and according to the Russellian constr ual the description "the table" should then miss its goal. It is incomplete in the sense where in order to denote an individual successfully, she should be completed like "the table of this room" (with an indexical) or like "the table of Russell's kitchen" (without indexical).

Different strategies have been followed to avoid this failure of Russell's theory (see Reimer 1998). One of them, favored by lots of semanticists, consist in saying that the interpretation of an incomplete description is $m$ ade possible as soon as one considers the description in its context of utterance: the context play a role in restricting the domain of relevant objects. For instance, interpreting "the table" is $\mathrm{m}$ ade possible uttered in a room, so that the context will implicitly restrict the course of values to the objects of the room. In some other contexts, for example if we were speaking about Russell's kitchen, the domain would be constrained by the

\footnotetext{
${ }^{10}$ See Rahman 2009 for an overview and a recent account in the semantics of fiction

${ }^{11}$ In some sense, we could say that since the translation into first-order logic of natural-language sentences is not expected to reach synonymy, Quine's criterion should not be expected to account for the m eaning of naturallanguage quantifiers.
} 
discourse preceding the utterance of the descrip tion in question, so that it would be naturally interpreted as denoting the table of Russell's kitchen.

Actually, such an analysis does the job not only for definite descriptions but also for other quantified expressions. For exam ple, when a speaker asserts to an audience "Everybody's tired now", this is not (in general) an asse rtion about everybody existing in the universe, but about the relevant people who are the other pe ople of the audience. Here too, the context plays a crucial role restricting the dom ain of interpretation of the quantifiers. Nevertheless, this is not the exclusive role of context re garding natural language quantifiers: context is required to disam biguate generalized quan tifiers between collective and distributive interpretations (see Hofweber 2000), e.g. between

"Four philosophers carried three pianos"

and

"Four philosophers carried three books"

where the usual interpretation of "three" (either three for each philosopher, or three for all) depends on the things to be carried.

The key role of context in natural language is thus not only due to the $m$ assive use of indexicals or of underspecified expressions. Frege's purpose of a Begriffschrift without ambiguous symbols, as well as Quine's intention to use only eternal sentences, could reach a situation where semantics is made context-independent. Nonetheless, as the above-mentioned cases indicate this is not sufficient to get rid of the issue: context plays a pervasive role in the interpretation of natural language quantifiers.

The linguistic situations on which Quine built his criterion appear to be very restrictive and artificial. Like Frege and Russell, he restricted himself to cases where context plays no role, hence to cases where language can be considered as a pure device well-shaped to describe the world. These are the typical cases where the repr esentational view of semantics can arise, in accordance with a universalistic conception of logic and language. By contrast, the way people use natural language in general, and quantifiers in particular, is context-dependent. The procedural view of sem antics is thus quite na tural as soon as one is interested in the way people speak and understand language in real situ ations. As we will now show, quantifiers in such a perspective cannot be linked to ontological com mitment as they are according to the representational view. Indeed, members of TSO are viewed as mere semantic artifacts, and no more as bona fide objects.

\subsection{Anaphora, skolemization, and quantification}

The so-called dynamic turn in Natural Language (NL) sem antics happened during the 1980s, as a response to the difficulties raised by phenomena like anaphora. Indeed, anaphoric pronouns - i.e. pronouns "co-referring" in som e sense with an antecedent expression (proper name, definite or indefinite description) - cannot be fully analyzed within first-order logic. Several reasons explain that fact, among which the following two ones:

(i) Anaphora can be inter-sentential, wher eas variables are not linked beyond one single sentence; moreover, in many other cases logical dependence appears to be at odds with syntactic scopes, as is shown through skolemization;

(ii) Anaphora involves information flow, beyond and above purely semantic information.

Inter-sentential linking can be shown th rough many obvious exam ples where a pronoun refers to an individual introduced in a preceding sentence, like in e.g.

"A man eats pretzels. He choked with them." 
Some of the simplest cases like this one coul $\mathrm{d}$ be processed using usual first-order logic with wide-scope quantifiers, so that the pr onouns (formalized by variables) of the second sentence be bound by the quantifiers of the first sentence. However, this method could hardly be expanded to a one-page discourse, and it does not work in the general case.

Indeed, several theories resort to choice and Skolem functions to account for indefinites or anaphoric pronouns. Such functions map non-empty sets onto one of their elem ents, possibly taking into account one or several objects of th e current domain. Whatever be the technical implementation, what is to be noticed here is th at such functions are required to process wide scope (Reinhart 1997) as well as narrow scope indefinites (Schlenker 2006, W inter 2004). In the example just above, a (constant) function $f$ would be introduced while processing " $a$ man", which could be used again to process " $h e$ " in the second sentence. To consider another, more interesting example, in order to account for the sentence:

"Every man loves a (certain) woman - his mother"

the following formalization is employed:

$$
\exists f[\operatorname{SK}(f) \wedge \forall x[\operatorname{man}(x) \rightarrow \operatorname{love}(x, f(x, \text { woman }))]]
$$

The principle benefit of such a formalization is that it enables one to make further anaphoric reference to the selected individual, which would not be the case using a standard FO formula like the following one:

$$
\forall x \exists y[\operatorname{man}(x) \rightarrow(\operatorname{woman}(y) \wedge \operatorname{love}(x, y))]
$$

where the scope of the existential quantifier $(\exists y)$ cannot go beyond the matrix of the formula. Yet, since such formalizations require functional quantification, shall we consider that our NL quantifiers hide second-order quantification? We do not believe so. The entities quantified over in the previous example are usual individuals - so what?

That puzzling situation is due to the $\mathrm{f}$ act that NL quantifiers do not just encode sem antic information, but also involve a proper dynam ic component frequently labeled information flow. Actually such a com ponent is already pr esent in first-order quantifiers. Hintikka (e.g. 1997) constantly criticizes Frege for his short-sighted conception of quantifiers as second-order predicates. According to him , Frege missed the point: quantifiers do not only pick out individuals from a domain, they do it in conformity with certain patterns of mutual dependence. For instance, when an existential quantifier $(\exists y)$ is in the scope of a universal one $(\forall x)$, its value will depend on the choice of a value for $x$.

As it seems, natural language uses many patterns of dependence and independence between quantifiers, and some of these patterns cannot be formalized within standard first-order logic. This fact basically explains the success of Skolem functions in NL sem antics, as well as that of other theories conceiving quantifier scopes as more liberated than in their classical understanding. ${ }^{12}$

\subsection{Presupposition}

One of the most popular theories in NL semantics since the 1980s is Hans Kamp's Discourse Representation Theory (DRT) (see Kam p 1981, Kam p \& Reyle 1993). It provides an interesting insight onto sem antic issues and their connections with ontology. DRT is a twostep semantic theory. The first step consists in the construction of Discourse Representation Structures (DRSs) which constitute the specif ic level of the theory. This is the place where anaphora resolution is handled. The second step is a $\mathrm{m}$ ore standard one, that of $\mathrm{m}$ odel-

\footnotetext{
${ }^{12}$ Let us mention branching quantifiers (Barwise 1979), Game-Theoretical Semantics and IF logic (Hintikka \& Sandu 1997), Dynamic Predicate Logic (Groenendijk \& Stokhof 1991).
} 
theoretic interpretation: it connects DRSs to standard model-theory. One can choose either an extensional interpretation structure or an intensional one based on possible worlds.

During the first step, DRT thus adds to the model-theoretic floor a representational level made of the DRSs. This supplementary level regiments some contextual information, e.g. the order of sentences, that does not appear in th e model-theoretic evaluation of discourses. A DRS $K$ is an ordered pair $\langle U, C\rangle$ composed of a universe $U$, i.e. a set of representatives (discourse referents, or reference markers), and of a set $C$ of conditions, namely the properties and relations ascribed to referen ce markers. During the discourse interpretation, discourse referents can be added to the uni verse independently of the presence of a corresponding entity in the dom ain of the interp retation model. Hence unlike other theories, DRT does not process the anaphoric relati on as if it were a genuine co-reference phenomenon: the ontological neutrality of DRSs allows accounting for anaphoric relations even in cases where there is a lack of reference.

More: as it processes every singular term, DRT system atically introduces a discourse referent into the universe of the corresponding DRS. In other words, the denotation of singular terms is automatically presupposed to exist. For instance, because most of the usual definite descriptions are incomplete, they are treated like anaphoric expressions: an antecedent is thus expected in the context of the utterance, i.e. a reference marker available from the DRS, so that the marker of the description can be identif ied with it. $\mathrm{W}$ hat does happen if no $\mathrm{m}$ arker was previously introduced? As the descripti on cannot be resolved, a m echanism of accommodation adequately extends the discourse context with a marker that can play the role of the antecedent (Beaver 1997: 976, 989-990). Th is mechanism therefore induces contextshifts in order to allow updates of DRSs so that the discourse process can go on. If a m arker is introduced by accommodation, it can nevertheless be later cancelled by some revision, such as in the following dialogue:

\section{A. "Santa Claus is coming." \\ B. "No, he doesn't exist!"}

Those pragmatic mechanisms of accommodation and cancellation appear to be unavoidable to account for the sem antics of discourses. As Pe regrin puts it: "For the sem antics to become really dynamic, we must turn denotations not only into 'context-consum ers,' but also into 'context-producers' - so that an utterance might consume a context produced by a preceding one." (Peregrin 2000). According to Groenendijk and Stokhof, this is even one of the $m$ ain characteristics of the dynam ic turn: "W hat is new, is the focus on context change: interpretation not only depends on the context, but also creates context" (Groenendijk and Stokhof 1999: 6).

The resort to DRT can be $\mathrm{m}$ isleading and sugge st that, as this theory stipulates an intermediate representative level between language and models, dynamic semantics requires a conceptualist or mentalist construal of sem antical interpretation. Semantics and logic would then collapse into psychology. Fortunately, th ere is nothing of the sort. DRT discourse referents are not to be thought of as "m ental entities": they are neither more nor less than the functional role they play in the theory, nam ely the role of antecedents in anaphoric processes; since anaphoric processes are fundam entally inferential processes, discourse referents are determined by their inferential role.

Can such considerations be transposed to m odel-theoretic individuals? It might be objected that if one goes back to the evaluation of DRSs (i.e. to the second step of DRT), standard semantics will take over so that e.g. the discour se referent connected with "Cinderella" have no semantic value. Nevertheless, the exam ple checked in this section indicate that two 
important features of DRT - the decoupling between the procedural and representational components of meaning, and the determ ination of the "referents" by thei $r$ functional role in the evaluation theory $-\mathrm{m}$ ight be not specific to this very fram ework but that they could be characteristic of dynamic (procedural) semantics in general. ${ }^{13}$

\subsection{Understanding, Phenomenology and Internal Truth}

Other analyses suggest a sim ilar sharp distinc tion between two levels. This is the case of Hofweber's (2000) conception of NL quantifiers . According to Hofweber, a separation is to be made between the internal reading or inferential role reading of quantifiers, and their external reading or domain conditions reading. The first case naturally occurs in sentences conveying partial inform ation, like in "There is someone Fred admires very much ", when Fred's attitude can be directed towards Sher lock Holmes, whereas the second case is obvious in "There is something to drink in the fridge ." Like for DRT, it seem $\mathrm{s}$ that linguistic understanding in concrete contexts only requires a neutral, procedural view of quantifiers, while the ontologically committing interpretation is put aside for very specific situations. How are we to interpret such inferential levels?

Several (maybe conflicting) interpretations of DRSs can be given. Asher (1993: 64) mentions three of them: logical form, partial model and mental representation. As we just said, the latter interpretation is escapable. Asher him self conceives of DRSs as homomorphic to the structure of mental states, i.e. as partial representations of the cognitive structure conveyed by the interpretation of a discourse. A m inimal interpretation of the DRT form alism would view DRSs as mere syntactic objects. According to such a view, DRT does not provide an extension of FOL in the usual sense: there is no real in crease of the expressive power of the language that would uncover some new features of the model-theoretic structure.

In any case, the principal goal of DRT remains accounting for anaphora resolution and some inferences can be handled at the proper level of DRSs, sparing us a detour by way of FOL (see Cooper et al. 1994: $54 \mathrm{sq}$ ). Of course it does not su ffice to qualify DRT as a non-syntactic theory, but it nevertheless gives its repr esentational level a sem antic flavor. DRSs must be conceived of as encoding the interpretation pro cess of discourse that $m$ akes further semantic interpretation possible.

Discourse interpretation can be carried out $\mathrm{w}$ ithout any confrontation with reality, i.e. without any sem antic evaluation. Except in th e case of underspecification, the process of construction of DRSs is alm ost completely independent from that of evaluation. Such a semantic restraint is of course assum ed for anaphora resolution, since an anaphoric link m ust be solved before any semantic evaluation. Besides, it has other advantages, such as providing a non-trivial interpretation of discourse about non- existent entities or resolving contradictions at the level of representations without a total collapse.

An immediate upshot is a possibl e account of truth at the interm ediate level. It is a local, internal truth, viewed as an another name for the consistency of the DRSs.

Even though one need not endorse a m entalist reading of DRSs (or of any other theoretical entity used to account for the procedural feature of meaning), it should be noticed that the way DRT processes language and presupposition is not far from phenomenological "bracketing".

\footnotetext{
${ }^{13}$ This seems to be Peregrin's viewpoint, when he ar gues for a general reduction of "reference" to "inference" via "co-reference": "If we recognize individuaries [sets of indi viduals contextually introduced by dynam ic semantics] and their inhabitants as mere tools to account for inferences, then the talk about reference becomes essentially parasitic upon the talk of inference - a referent is nothing more than an illustrious clamp holding certain inferentially related expressions together." (Peregrin 2000)
} 
In some sense, dynam ic semantics provides a picture of the way people reach an internal perspective onto the world through discourse interpretation.

\section{Towards a neutral semantics}

As was seen in the last section, several NL phenomena show to be irreducible to a $\mathrm{m}$ ere analysis within first-order logic, i.e. within the locus naturalis of Quine's criterion. Sem antic analysis requires a procedural approach as a first step, corresponding to the way people interpret or understand NL utterances, before any possible more classical and ontologically committing account, connecting interpreted langua ge to world. The ontologically-neutral conception of semantics put forward in the pr eceding section allows many choices forbidden to model-realists so that our (procedural) theories suitably account for our linguistic intuitions. According to such a neutral view, procedur al semantics only targets $\mathrm{m}$ odeling linguistic meaning, whatever the world may be. Expressed in the Quinian idiom: the neutral view leads to a naturalization of semantics, and to an anti-revisionist strategy.

Focusing on the cognitive value of any usual proper name (empty or not), a naturalized conception of sem antics will naturally favor some uniform analysis and account for the aforementioned case of "Santa Claus" in a child's way. With this broad (ontologically) neutral view, what is expected from theories is a meaningful account of the contribution of contextual domains of discourse to the sem antics of se ntences: ontological considerations about the status of dom ains are beyond their subject $m$ atter. If a theory targets a true description of linguistic meaning, whatever the ontology, it needs no artificial (m etaphysical) metatheoretical constraints on the constitution of TSO: neutral semantics is hence characterized by a kind of meta-theoretical freedom.

TSO variability ("ontological relativity"), as it is induced by m odel theory, needs not be restricted. Defined as relative to a structure, the Tarskian concept of truth should not be thought of as the universalistic, absolute one. No $\mathrm{r}$ should one consider such and such TSO as composed of bona fide objects. MR appears thus to be a coarse transposition of the universalistic outlook to a frame where it becomes senseless.

We can now sum up the results of the first part of this paper, in a few points:

(i) Semantic values, including truth, can be c onceived of either in a procedural way, as internal to the interpretation level of discourse, or in a representational or referential $\mathrm{m}$ anner, as resulting to some relationship between language and the external word;

(ii) Internal semantic values, including internal truth, are sufficient to account for linguistic understanding; they are disconnected from any ontological commitment;

(iii) Quine's criterion $\mathrm{m}$ ay be relevant as $\mathrm{f}$ ar as we are concerned with representational semantics, but not at all when considering procedural semantics, i.e. the interpretation level of language.

The intermediate conclusion reached so far is the lack of general entailm ent between truth and ontological com mitment. However, for fiction it $m$ eans that we avoid com mitment to fictional objects just acknowledging a kind of internal (procedural) truth. In the second part of the paper, we will claim that fiction can also be true in a strong, external sense. Of course, it cannot be done using representational semantics - if it were done that way, one would have to restore Quine's criterion and ultim ately admit of fictional objects. We will defend that the connection between fiction and the external worl $d$ is not a kind of representation, but another one; and since fiction is, in some sense, indispensable, it can be considered as genuinely true. 


\section{Part 2. TRUTH FORM INDISPENSABILITY}

In this section, we will rely on the Indispensab ility Argument in order to argue in favor of the utility of fictions which implies then that fictions are true. The issue is thus no $\mathrm{m}$ ore that of truth within fiction, but that of the truth of fiction. The underlying idea is that fictional narrations do an interpretative use of language, and not a descriptive use; by this way, they could avoid being the matter of theoretical condemnations.

We will exploit literary criticism and philo sophy of art to support the dem onstration. Moreover, we chose to focus on novels and thoughts of novelists ${ }^{14}$ since they are a good illustration for our purpose. Af ter trying to speci fy the indispensability of fictions, we will secondly precise which kind of truths they seem to express.

\section{The "Indispensability Argument" and its revision}

Historically, the so-called argum ent has been developed by Quine $(1948,1976,1981)$ and Putnam (1979a, b) as a contribution within the philosophy of $m$ athematics. Because mathematical theories take a central place in ev ery branch of empirical science, philosophers began to argue that they are indispensable in th at sense, and furtherm ore, that this kind of indispensability, according to the line of the argument, gives us good reasons to believe in the existence of mathematical entities. In other word s, we can use this strategy to reinf orce the thesis of mathematical realism: "reference to (and quantification over) mathematical entities such as sets, numbers, functions and such, summaries M. Colyvan (2008), is indispensable to our best scientific theories, and so we ought to be com mitted to the existence of this mathematical entities". Of course, many other forms of the Indispensability Argum ent have emerged since then, and precisions as $\mathrm{m}$ uch as adjustm ents have been proposed, especially concerning the way we have to understand the $\mathrm{m}$ eaning of this indispensability. W e will not rejoin the debates about the classical version of the argument. Let us just try to exam ine how it can fit to the case of aesthetic fictions.

First of all, our interest is not oriented to the defense of fictional entities, since we argued in part 1 that no ontological commitment necessarily results from the truth of fictional discourse. Then we must cut off the inference from indispensability to the existence of the entities in question. What is left is the very idea of indi spensability. But here again, it is quite im portant to notify that fictions are not essentially determined by an hypothetical, even successful, applicability to em pirical sciences, neither by any kind of pure descriptive or explanatory functions. Therefore, the weakening revision of the argument is operated in order to dism iss the original link between being indi spensable, and being indispensable to our best scientific theories, which means to renounce to the idea of a theoretical indispensability. ${ }^{15}$ The reason is the distinction we assume between two uses of language: the descriptive use, im plied by the classical form of the argument, and an intentional use, expressed in all discourse participating of our practical apprehension of the meaning of events or behaviors. ${ }^{16}$ This contrast allows us

\footnotetext{
14 The term "novel" must be taken in its common meaning. In particular, that is to say we don't assume the distinction by N. Frye (1957) between "novel" and "novelist".

${ }^{15}$ It could be viewed as a general ization and an ext ension of Quine's holism beyond its original boundaries, as was suggested to us by J. Morizot.

${ }^{16}$ It is worth noticing that like in Part 1, we want to ground truth into interpretation. Here, the question is that of the interpretation of people, actions, etc. ; by contrast, in Part 1 the issue was that of linguistic interpretation. What is common between the two cases is the objective to account for truth without description, hence without ontological commitment.
} 
to think that fictions are rather based on the latter, since they do not seriously describe the world. So, they are not stricto sensu indispensable to our best scientific theories, but to our best understanding of the signification of life. In what follows, we are trying to grasp something like the practical hermeneutical weighting of fictions.

Besides the ontological reading of the Indispen sability Argument, there is another one. In fact, if we adm it that $\mathrm{m}$ athematics, or now $\mathrm{f}$ ictions, are indispensable in any sense, then mathematical or fictional discourse must be considered as true. It seems hard to deny the truth of mathematical theories in re gards of their em pirical success; then it would seem hard to deny the truth of fictions in regards of their pr actical success. But this is quite odd! At first blush, fictions are qualified as false, wrong, even malicious, and literally defined as nonserious discourses, for the very reason that it is fictional. Consequently, our goal is first to give an account of the specific indispensability of fictions, and secondly to modify, at least to justify, the idea that fictions tell us som e true things about the world and human beings - we will try to make clear which kind of truth it is.

One last point before entering the dem onstration: contrary to m athematics, fictions are not in themselves a priori indispensable, in the sense that they are not created in order to explain the reality, describe what there is or im prove our knowledge about the world. ${ }^{17}$ They are not produced to be scientifically, em pirically or theoretically useful. Thus we could say that fictions are not indispensable, but it is yet $\mathrm{i}$ ndispensable to have fictions: once it has been written or film ed, once there are fictions, a nd even if each fiction separately is not indispensable, we must observe how $\mathrm{m}$ uch it can help us to interpret and understand som e features of the world and of human attitudes. ${ }^{18}$ In that sense, we will try to defend that fictions are a posteriori indispensable for the reason that using this kind of tool im proves our general and intentional capture of life.

\section{Being indispensable is equivalent to being useful and non-reducible.}

\section{"I've read a lot and I do understand what's the point" R. Gary, Les racines du ciel.}

Fictions are usually thought as being useless: telling stories would alm ost be the sam e as telling foolishnesses. This point of view can be met both in everyday-life and in philosophy, as it is som etimes implied by som e logical i nvestigations, moral considerations or even aesthetics thesis. All happens as if there was a sort of common agreement about the idea that fictions, because they are literally fictional, are non-serious illusionary discourses, and consequently, neither indispensable nor true. Recall the condemnation by Plato in Republic (X 605d-606c), by Furetière (1666) in the XVIIth century in France, by Frege and Russell claiming that all fictional sentences are never true ${ }^{19}$. In fact, this kind of allegiance seem $s$ to be the current beginning for all philosophical anal ysis of the status of fictional narrations. More recently, P. Lam arque and S.H. Olsen (1994) have also argued in favor of the contra-

\footnotetext{
${ }^{17}$ We could nuance this claim by distinguishing between fiction and myth: the latter might have been initially considered as a story which was created in order to explain the origins of the world. But it was still a sym bolic description rather than a theoretical one.

${ }^{18}$ It is clo se to the thesis of aesthetic cognitivism in its epistemic way - distinct from its aesthetic way. See Darsel, S. \& Pouivet, R. (2008).

${ }^{19}$ More accurately, fictional propositions are considered as always false by Russell, and without any truth-value by Frege.
} 
truth tendency about literature, but they defend at the sam e time a humanistic conception of fictions, which recognize their indispensability ${ }^{20}$.

On the other side of extrem e speeches, as Bouveresse outlines (2008:13), we encounter some mystical defenses which laud the superiority of the fiction within the magical quest for Truth. Here, only pieces of art and literature (or poetry) can reach the very deep and essential truth of Life, and it goes until the claim that fictions are the truth itself. We will not argue against this faith, for it is quite excessive and far from being rigorously argued.

In order to contest the utility of fictions, pe ople and philosophers actually adopt a scientific outlook, assuming by this way that fictions use the descriptive function of language. If they would really be written in a descriptive sigh ting, then nothing will distinguish them from science or philosophy, and at worst, they $\mathrm{m}$ ight be judged as elim inable. In particular, the explanatory mission of realist and naturalist novels from the XIXth century, Balzac's or Zola's ones for instance, and their presumption to be objective and impartial, could be thought as directly challenging the goals and $\mathrm{m}$ ethods of empirical sciences. In this case, the utility would be quite relative, since we $m$ ay wonder why then these novelists choose a fictional treatment for some questions which receive a best analysis if studied by hum an sciences like philosophy, or nowadays psychology. The com petencies, abilities and efficacy of fictions, in comparison with serious theorizations, seem to suffer the very choice of the narrative way.

The problem stands in the confusion between the two uses of language. W hen we say that novels describe some features of the world and human hearts, we m ust not strictly take the term "description" in its scientific and refere ntial meaning. Fictions do not describe anything in this manner; actually, fictions are always a medium for interpretations. In other words, those who claim that fictions are useless, in fact look after a pure descriptive use of language, and then, being disappointed, they discredit all kind of indispensability of them . But if we bring to light that fictions express an intentional use of language, if we really differentiate the serious and the non-serious discourse by this wa y (regarding dissimilarities of methods, ends and objects), then we are apt to show in wh ich sense non-serious non-descriptive narrations are indispensable.

Before demonstrating this point, it is rather important to precise one last thing. Som eone could object us that we are making an instrumental use of literary creations. This is obviously not the case. Outlining their possible utility is not the sam e as reducing them to their practical helpfulness. Indeed, fictions do have $\mathrm{m}$ any other aspects and purposes, like precisely being absolutely not created in order to be useful, or used, like being just aesthetic products. Then we give our attention to their indispensability only in the context of the debate concerning the truth (or falsehood) of fictions.

\subsection{Utility of fictions}

We precise at once the kind of utility we argue for, i.e. a practical utility. Certainly, f ictional creations do also have $m$ any other utilities: accord ing to different authors, they can console our grieves, they can answer to some primitive needs, they can incite us to social revolts, they can purify our souls, and so on. But here, the idea is that fictions, and novels in particular, are useful for our apprehension of life. ${ }^{21}$ So, the reasons why novel is practically useful - in order

\footnotetext{
${ }^{20}$ Their proper view is to claim that "the concept of truth has no central or ineliminable role in critical pratices", or in others words, that "there is no significant place for truth as a critical term applied to works of literature" (1994: 1). Lamarque and Olsen are not reticent to th e idea of a specific cognitiv e function of fiction and literature, but separate this question from the question of truth. On this point, we might disagree.

${ }^{21}$ This idea echoes with W. Benjamin's study about the function of the "narrator". See Benjamin (1936): “a narration comprises openly or secretly a utility. [...] The narrator is of good advice for her audience".
} 
to understand more accurately the real worl $\mathrm{d}$ and people - are $\mathrm{m}$ ultifaceted. We will now make an inventory of them, mainly due to literary criticism, from the least to the greatest specific function.

(i) Descriptions. Surely, it holds a heuristic value, b ecause it taps and reveals some aspects of reality still ignored. It could be considered as a kind of concurrent for the historian, as many authors have said. For exam ple, Hugo defines himself as an "historian of custom s and ideas", of "hearts and souls" (1862). Novelists, like J. Austen, M. Yourcenar, H. Jam es, and almost all writers would be able to deliver some traits of hum an psychology. Then fictions seem to offer knowledge about human beings and reality, operating as a source of information which are not found elsewhere. But, as we have said before, this way of speaking is a kind of "naïve" view: it is not a word-to-word vision of the utility of narrations, and it is not at all their very specificity; again, fictions are useful to interpret the world.

(ii) Spreading. Novel conveys and broadcasts som e scientific, philosophical or $\mathrm{m}$ oral knowledge, like so-called Lucretius' or Boileau's didactic poems, or like La Fontaine's tales. Its value here is then didactic, but once again, not characteristic.

(iii) Abilities. Novels can expand and im prove our mental faculties (intellectual and sensible), and particularly our m odal competencies, as following R. Pouivet (2008), just by telling and listening to stories. This is one of the ideas developed within the aesthetic cognitivism thesis. Here, its value is cognitive, but once again, not characteristic.

(iv) Distance. Novel questions and shakes som e dominating viewpoints, offering new prolific perspectives about what happened, wh at is hidden under a uniform social discourse, what looks like being established. Its value here is critique, and we can think about polemic or provocative stories, or about som e various notions which are turned round - barbarity, with Aeschylus, Flaubert or J. M. Coetzee; stupidit y, with G. Grass or I. B. Singer. Once m ore, highbrow essays could do the job, but we could - and we will - argue that there is a special flavor of fictional criticism.

(v) Arranging. Some novelists are trying to arrange a nd give a significant structure to all kind of facts or knowledges, in order to redu ce the feeling of chaos and gibberish we $m$ ay have about the world and the way we speak about it. For authors want to $\mathrm{m}$ ake sense, they take over and condense intellectual, social a nd empirical matters, including them in a story which seems to be based on encyclopedic designs. Think of R. Musil, H. Broch, J. L. Borges, Flaubert and, today, som eone like P. Senges. So me commentators consider that tendency to be a taxonomic obsession. Here, the value of the fiction is rather synthesizing, which is much more specific to it because it is meant to interpret the heterogeneousness of the world.

(vi) Surveys. Novel studies and clarifies in a deep analysis som e known features of the reality, by extending our intentional word list. V. Descombes observes that reading stories gives us an "enlightenment of our vocabulary for the description of hum an areas" (1987:16). We begin to im prove our consciousness of vari ous aspects of life, those which are not so obvious. For instance, $\mathrm{m}$ oralists such as $\mathrm{La} \mathrm{Br}$ uyère, or dram atists such as Corneille or Molière, reveal som e dark parts of the functioning of our passions. More generally, digressions and meditations within the plot do play this role, as M. Kundera outlines it (1986). And the efforts $m$ ade by $m$ any authors to grasp, for instance, the spirit of a city $m$ ay be thought in this perspective (like Vienna seen by T. Bernhard, R. Musil, E. Jelinek...). This is a characteristic value of the novel to be analytical, and being as such, to be pedagogical. In fact, it educates our perception, offering us the possi bility to becom e more attentive to som e 
ordinary things. I. Calvino defines for exam ple his book Palomar as being a "pedagogy of look and of thought" (1985).

(vii) Readings. Finally, last but not least, novel is a creator of significance. It suggests different interpretations of hum an behaviors and social phenom ena, developing different decoding frames of the world. Polyphonic novels illustrate it very well, like A. Kristof's trilogy, L. Durrell's Quatuor, or J. Barnes's Talking it over: intertwining of viewpoints allow the reader to $m$ ultiply the meaning of the story, and consequently, of life. Moreover, some novels are bound on som e sort of metaphysical hypothesis, in the trivial sense; they are then apt to help us to have one of the possible understandings of the meaning of reality. Following Kafka, Dostoïevski or Beckett, we are invited to read the world in light of its absurdity, its tragicomic side. Its value is therefore hermeneutical.

In brief, (vi) and (vii) are the central c ontribution we claim fictions do provide. It characterizes the very specificity of the utility in question. Furthermore, (iii), (iv) and (v) may be considered as m odalities, means or even resu lts of this particular utility. The $\mathrm{m}$ ark (i) is controversial, depending to what we $\mathrm{m}$ ean by "description", and (ii) is quite contingent, exemplified by many novels, but not only by them . The entire inventory leads us to assert that, pace Plato and Quine, fictions are undoubtedly useful.

\subsection{Non-reducibility of fictions}

The indispensability of fictions has actually to be def ined by two $f$ eatures: to be usef ul to understand the world and the hum an existence, and to be non-reducible to other expressive media. We do need to give an account of the very specificity of the practical role of fictions. The fact that fictions are indispensable $m$ eans then that they are necessary in order for us to have a better understanding of the world. So, the validity of the argument supposes the idea of a success implied by the account of fictions with in our hermeneutical apprehension, a kind of superior efficacy, which can not be found anywhere else. This is why we have to specify their indispensability, in order to dismiss their possible contingency and eliminability.

Novels are irreducible if and only if we ar e successful in dem onstrating that we cannot paraphrase their content into another form ulation, because it would im ply that we can eliminate the fictional turn in favor of a theore tical, or at least descriptive, use of language. The possibility of being dispensable definitely asks for a possibility of translation, as a canonical logical notation is supposed to provide. The point is that, even if it looks like possible to reduce some fictional propositions at a local level, it still rem ains hard to apply it at a global level. The teaching lesson we could ex tract from a story does not express at all the whole hermeneutical process in progress. Why is it so? Six features can be sketched out.

(i) Complexity. As Kundera claim s, "the spirit of the novel is the spirit of the complexity"(1986:30). According to him , the "eter nal truth of the novel" is to say to the reader that "things are $m$ uch more complicated than you think". Moreover, Kundera emphasizes that the particularity of the hermeneutical utility of fictions has to struggle against the tendency to standardization: "the novel is al so [like the world] wo rried by the termites of the reduction, which do not only reduce the meaning of the world, but also the meaning of the oeuvre". What is crucial is then to take into account and save this pluri-interpretability.

It goes together with the ironic, hum oristic and playful dimension of the novel, which is at the same time a dimension of the offered understanding. It pushes away and question our theoretical grasping of real events. Furtherm ore, because fictions enjoy the privilege of an entire freedom of treatments for serious them es, authors are allowed to draw aside rational norms, scientific requirements or reasonable vi ewpoints in order to create stim ulating echoes of signification. According to D. Rozakis, novels are attached to the praxis, and the function 
of imagination is to show that there is no strai ght a priori rule to know if som e principles are controversial, neither when nor how (2009: 18). So, contrary to the theoretical sphere, and then to the descriptive use of language, the fi ctional use assumes partly paradoxes and their evocative power.

(ii) Non-actuality. Novelists are looking for significations beyond what actually exists or happens. For instance, the way R. Musil presents some facts in The Man without qualities indicates that the bundle of possible m eanings of one event, such as it could have happened, or even such as it should have happened, is m uch more important for our apprehension of the deep meaning of things than the event itself . The idea is to dism iss the privilege of a literal one-dimensional viewpoint on actual reality. D. Ro zakis claims also that "the interrogation about human businesses requires the fiction, which is not the description of existing custom $\mathrm{s}$, but the quest of a future good" (2009:15). The entire axiological dim ension of fictions is linked to this deviation from the current data.

(iii) Symbolizations. Fictions are generally based on the use of sym bols and metaphors. The specificity of these non-literal expressions is to have m any possible interpretations, at least several variable ones. The novel is the ar $t$ of detail: its irreducibility com es from this evocative brightness of concrete things, consider ed at first blush as trifling insignificant dust. And sometimes, in this perspective, we will be urged to read the story of one $\mathrm{m}$ an as a relevant mirror of the general human life. The process is therefore much more analogical than logical (in the trivial sense) or explicative, because the $m$ eaning stands in em blems and pictures, rather than in formal argumentative systems.

(iv) Content-form dependency: local level. There is a necessary inseparability between what is written and how it is written, between what the story tells us and how it tells it. This is the reason for choosing the narrative way rather than the theoretical descriptive one. $\mathrm{V}$. Descombes notices that an idea becom es really novelistic "when the writer found a way to 'analyze' it, i.e. to change it into a schem atic scenario" (1987:90). The point is that the specificity of fictions results from a narra tive analysis of called up concepts, ideas or questions, like for example the degradation of values in Broch's famous book, or the adultery in Anna Karenina. Therefore, this will be through the st ory that the reader is going to follow gradations, developments and contents of one or many (theoretic) thoughts. In this sense, it is difficult to think we can strictly paraphrase wh at the fiction says, and then im possible to reduce its structural aspect which is what is us eful to understand the reactions or choices of a character - and, by extension, of a hum an being. It is involved by a kind of heterogeneous dynamic impulse. J. Rivière (1913) distinguishes the poetical emotion from the novelistic one, precisely because the latter ensues this chronological movement: we progressively understand, neither instantaneously nor directly; and the content is not fixed but changing.

As a consequence, fictions allow us to test the full meaning of some concepts, by means of putting them into a plot, or incarnating them into a character. The idea is that an a priori theoretical treatment of them would not disclo se many features of these concepts, like for example practical effects they could have in our "real" existence. In another words, the "veil" of imagination plays the role of an intentional adjuvant which prevents $f$ rom (1) the paraphrase by a docum entary or a system atic theory, and (2) the possibility $f$ or the fictional discourse to be a descriptive one, even if it can integrate various descriptions. Thanks to this specificity, what seem $\mathrm{s}$ to be descriptive and th en eliminable, is in reality $\mathrm{m}$ ingled into an intentional and aesthetic frame, impossible to separate, and which transforms the content as a contribution for the apprehension of the world. The slogan $\mathrm{m}$ ight be: For each different expressions, different interpretations of the signification of some ideas . In general, a movie, a comic strip, a cartoon, a novel do not assign the same practical lights on us. 
(v) Content-form dependency: global level. The work of representation itself seem $s$ to endorse significations. ${ }^{22}$ We might think that the indirect im itative process possesses in itself an hermeneutical value, for it structurally organizes words and our world. The spirit of nomenclature OuLiPo's writers display is a $\mathrm{m}$ atter for the idea that form al properties, even arbitrary chosen, perm it us to read the reality through different angles, and then to offer different intentional hypothesis. Sim ilarly, the stylistic and poetic aspect of fictional discourse, playing with rhythm $\mathrm{s}$ and sonorities, also involves a kind of intentional apprehension which is far from being subject to paraphrase. How could one rightly elim inate the musicality of a tale?

It is close to Goodman's idea, according to which "understanding and creation go together" (1978). Next J. Morizot (2008), it $\mathrm{m}$ eans that (1) contem plating an artwork or following artist's intentions does not exhaust what ha $\mathrm{s}$ to be understood about the artwork, and (2) creation is the $\mathrm{m}$ ost fruitful form of unders tanding because it has to father first its own conditions of relevance, and then to give to them a form which can be com municated and shared. The same for fictions. Neither interpretations of a myth or multiple readings of a story do certainly exhaust their respective $\mathrm{m}$ eaning, nor does the $\mathrm{m}$ eaning of som e extracted concepts. Furthermore, the creative construction of a plot and various characters is also a moment of fathering relevant conditions, i.e. giving a consistency to the narration, as well as a moment of an intimate understanding of what is involved in.

(vi) Incompleteness. Finally, novels are like open fram es. They produce a sort of fragmented meaning, unfinished, intermittent and out of systematization. This is one of the reasons which explains why the question of th e reception and the job of the reader are so important. In other words, fictional contents can not be reduced to positive fixed knowledge, because fictional statements are always incomplete, expecting an interaction with us. In fact, it is incom plete because (1) there are som e questions about a story which are neither checkable nor answerable, and (2) there are some hypothetical interpretations which depend on the inner and outer context, i.e. the context of the story itself, and the context of the reader. Following (1), we m ay say that, contrary to desc riptive discourse which is considered to be underdetermined, but can be completed, fictional discourse is undetermined, and then we may conclude that it precisely allows us to propose several interpretations. But this $\mathrm{m} u$ ultiinterpretability is not only implied by the first sense of incompleteness. Indeed, following (2), it looks as if the meaning of present fictional data is in itself interpretable in many ways.

Of course, it does not mean that we could carelessly interpret, for we ought to keep in m ind the line of the text. We just want to say that fictions are like centripetal media: their meanings are impossible to reduce, alike the $\mathrm{m}$ eaning of the reality, and their open dim ension gives right to Calvino when he wrote that novels are more clever than novelists! The fact that we can again and again interpret one story leads us to suppose we can do the same for events and choices in our real existence. The slogan is: For different interpretations of the fiction, improved abilities and different intentional interpretations of human life $\quad .^{23}$ This $\mathrm{m}$ anyhermeneutics of fictional narrations com es from the variability relative to each reader, ages, thematic stresses and so on. In short, we clai $m$ that there is no single interpretation of one novel, and that no fiction offers one single interpretation of the world.

\footnotetext{
${ }^{22}$ This is one of the principal reasons why the question of the translation of literary works is very problematic. We will not enter this complicated debate here...

${ }^{23}$ We will here distinguish aesthetic fictions from scientific fictions. The reason is that the form er are persistent because they are overall content-form dependant, whereas the latter are d eciduous and close; they do not adm it different interpretations as much as fictional hypotheses do.
} 
Once again, argum entation goes from the least to the greatest specificity of the practical utility of novels. But each feature contributes to support the idea that fictional discourses cannot be eliminated or translated into a pur e descriptive language. And therefore, fictions break out as being really indispensable for our grasping of the intentional side of the world.

\subsection{The relation between fiction and reality}

The principal problem that the idea of a practical utility of fictions presupposes could be that we have to accept a necessary relation between fiction and reality. More exactly, the question is first "Are fictions linked to the real world? ", but especially "How?", since we com monly oppose real and fictional universes. Our thesis does indeed im ply a porosity between these two universes, maintaining at the sam e time a distinction between them . But the fact is that we disagree with contrary theses such as th e formalist one, the self -referential dimension fictions would have, or Baudelaire's claim about the autotelic value of pieces of art or literature (1857). In particular, Genette's idea of a watertightness of fictional worlds (1991: 58-60) appears to be quite erroneous, for it $\mathrm{w}$ ould imply that novels can not be useful to anything but themselves and literary history (see also Macdonald 1954).

Aesthetic cognitivism does also suppose som e connections between reality and fiction. In fact, if we learn from fictions some things about the real world, we will be inclined to assum e that this is because of such a link. And even if novelists choose to speak about, not the actual reality, but a kind of ideal one - the way things should happen, instead of the way they really happen - it nevertheless does not prevent us to think that this $m$ oral and modal quest stands closely to what we may call the true human existence. According to E. Fraisse \& B. Mouralis, this abstract im agined reality is not less real , because "its advent is considered as being possible" (2001: 152). Measures of probability and credibility concerning novelist $m$ oral considerations entail then a dialog between what is in the fictional frame, and what is out of it.

What fictions helps us to understand belongs to reality. But it differs from descriptive or theoretical explanation because it is much more an interpretation of it than a knowledge about it. On one side, there are pure hypothesis, on th e other side, future thesis. The intentional discourse in fictions can not be corroborated or confirmed by means of empirical experiences, observations or experimentations. Yet, we could judge that a fiction is not credible or lacks authenticity, if the interpretation of the reality it proposes seems partial or incoherent. Validity then results from the application of some criteria like for example the unity of the narrative plot, the respect of good $\mathrm{m}$ anners, the laws of the literary genus, and of course, the way it echoes with real data - human feelings, human behaviors, social functioning, etc.

Consequently, fiction and reality do support $\mathrm{m}$ any links; they enrich one another. Fictional universes possess a lot of similarities with the real one - objects, rules, individuals, spaces and on the other hand, reality blends fictional parts - nam e of som e characters, possible interpretations of events. Even if the latter seems to be an analogical relation, it is still a relation, and we just need that idea! So, fictions are indispensable, because they are useful and non-reducible, and they are indispensable to our understanding of the single shared reality.

If so, we can $f$ ollow the line of the Indisp ensability Argument and directly claim that fictions, because they are specifically indispensable for a better understanding of the world, are true. We managed then to enter the fictiona 1 discourse within the scope of som e serious practical contributions about reality. Incidenta lly it shows that our concept of truth is not antirealist: even when applied to non-descriptiv e discourses it is still linked to reality via 
practice, as is stated by the Indispensability Argument. ${ }^{24}$ But of course, it may be odd: fictions are telling us som ething true, being sim ultaneously false illusionary creations of our minds. That is why we must precise the nature of these fictional truths.

Does it follow the schem e of the truth-corre spondence, based on Aristotle's definition of adequatio intellectus et rei - "to say of what it is that it is" is true ? It cannot obviously be the case here, because fictional discourse is by definition out of a direct descriptive relation to the real things. Then is it a built truth, only occurri ng inside the fictional domain? But we would be confronted to the problem of the literal true statements we can read in a story. In short, how is the concept of truth modified when applied to fictions, and in which sense do we claim the existence of something true in and $\mathrm{f}$ rom them? The point is no $\mathrm{m}$ ore to argue for the acknowledgement of som e truth for fiction, for we consider it now granted by their indispensability. However indispensability only delim itates the extension of the concept of truth, and one can hope for $\mathrm{m}$ ore than that. In order to sketch out som e more intensional account, we will take care of what literary critic ism, philosophy of art and effective practices of writers and readers say about this matter.

\section{Truth of fictions and truths from fiction}

According to Lamarque and Olsen, there would be no reason to consider the notion of truth as a central one when we critically analyze fictions and try to characterize their aesthetic value (1994). Let's be clear once again: we do not pret end to calculate the power of fictions in regards to their truth degrees; we just argue th at, because they are practically useful, they do present to us, am ong others, some true interpretations of the world and som e true intentional hypothesis about human businesses. The kind of $\operatorname{tr}$ uth they involve is rather objective than personal, even if there can be different subj ective ways through which one character sees the world. Truths from fictions are public and deba table, for they are spread and $m$ ade objective by the writing itself.

We have to precise that there are many sorts of truths within a story: fictional truths are next to non-fictional serious referential ones. In other words, we must distinguish, here again, those which are specific to a narrative treatm ent of som e subjects. Jum ping ahead the demonstration, we can notice that they are, like their utility, characterized by an essential interdependency between content and form. As from the moment we would be able to $\mathrm{m}$ ake the propositional content autonom ous, then rises the suspicion of a reducible truth, apt to occur in a theoretical discourse.

Some distinctions are therefore necessary to de termine the very nature of truth in fictions: on the one hand, the difference between propositional and non-propositional truths, and on the other hand, between literal and non-literal truths. We will see further how it works. Moreover, it is important to keep in mind the slight difference between what is true and what belongs to the notion of verisimilitude - as Aristotle def ines it in his Poetics -, for it is sure that the moral and modal quest of novelists pertains to it. ${ }^{25}$

\subsection{The possible eliminability of factual propositional truths ${ }^{26}$}

\footnotetext{
${ }^{24}$ Our proposal mainly consists in widening the scope of the concept or truth. Truth of descriptive discourse can be viewed in many ways compatible with the Indispensability Argument, hence still being compatible with our account.

${ }^{25}$ See Genette (1969: 74) about the difference between the notion of verisimilitude and the notion of motivation.

${ }^{26}$ Eliminating the factual truths which occur in fictions is possible, that it to say it is possible to extract them from the story, but it is obviously impossible for the novel itself to run without, unless being another one.
} 
When we read a novel, we sometimes read statements which are literally true, i.e. referential and for which the schem e of truth-correspondence does apply. Of course, these propositions are what J. M. Schaeffer calls "the tracks of the non-fictional universe within the fictional universe" (2008: 79). They can actually be checked by em pirical facts. At this first level, being true means being sticking to the reality.

The entire documentary dimension of novels co mes under this kind of truth. The plot will have an historical and social context which has really existed or actually exists. This is the case of naturalist novels which give us inform ation about the conditions of the French society at that time. Fiction is then apt to provide some true account for historians: novelists do the job of registering various facts. Zola's use of exact nam es of tools $\mathrm{m}$ anipulated by each corporate body illustrates it, such as Hugo's w ill to integrate slang within his writing or DeLillo's approach to $f$ inancial operations which really happen in our (crazy) world. Moreover, novelists can use real persons as characters for their story, incorporating biographical data within the narration. For exam ple, S. Strindberg recently wrote a novel for which the principle character is Valérie Solana s, the woman who really tried to murder Andy Warhol.

Another kind of literal truth com es from the theoretical dim ension of various fictions. The didactic aim of many of them, the encyclope dic tendency of novels which integrate fixed knowledge, the essayist aspect realized by the pr esence of digressions or abstract m editations within the story are occurrences of this intrus ion of serious discourse inside the fictional world.

We do agree with the conclusion that it does not allow us to say neither that $f$ ictions are indispensable for doing that job, nor that there really exists some fictional truths: this kind of truth is not specific to the fiction, since we can reduce it to serious statem ents about true facts already known. Nevertheless, it allows us to make two comments: ${ }^{27}$

(i) Factual propositional truths in fictions perm it to give an account of effective practices, those of readers and of writers (see Fraisse \& Mouralis 2001: 196). A reader can find and learn some true information during his fictional pastime. A writer may want to use his or her novel to spread on som e true but not enough known facts. For exam ple, literature from formerly colonized countries can be considered as having often been built on this willing to show the reality of a culture, a nation.

(ii) This kind of referential truth is what we will use to give an account of the literal truth of true statements in the fiction. In another words, it is clear that fictional truths are based on many ordinary empirical truths about which we obviously agree. When a novelist for example writes that his character is eating such and such meal, or walking on such and such street, it is nothing more than what we notice as being true in our everyday life. However, this is exactly what science-fiction or fantastic novels will $\mathrm{m}$ odify, specifying that, for exam ple, in this fictional world, human beings fly or eat pure red energy-bubbles.

\subsection{Interpreting facts: a two-level truth}

Besides non-fictional truths, it seem $\mathrm{s}$ that there are som e truths em erging from a fictional frame of investigation. This is the case of so me statements which can be considered as literally true (non m etaphorical), but im possible to em pirically certify, and non referential. They propose instead an interpretation of fact $\mathrm{s}$, a particular understanding of things which

\footnotetext{
${ }^{27}$ Besides the fact that it is still an argument in favor of the idea that there is indeed something true within the fictional language, although almost trivially. It might be useful to notice it in order to dismiss radical claims such as those of "contra-truth" for which it is said that there is no reason at all to keep talking about truth into critical analysis of literature.
} 
happen in our real world and of hum an behaviors, relative to a general viewpoint or to the point of view of one character.

Indeed, when Balzac (1842) confesses that he tried not only to reproduce a sort of mirror of the society, but also to explain something like the "hidden signification" of the architecture of social and psychological facts, then he was tr ying to produce som e true statements different from descriptive ones. These propositions expressed by what we call the "present tense of general truth" are a m atter for a second-level truth which is not anym ore an adequacy to factual realities but an explanative hypothesis am ong others which is offered by the fictional frame. As he wanted to describe the spirit of his time, he was actually interpreting facts, and these interpretations are what we $\mathrm{m}$ ay judge as a form of novelist truth. So, efforts of global understanding of a particular situation imply propositional truths, but non-reducible.

Besides the construction of true expressions about social contexts, novelists seem to be concerned to say some truths about our feelings and vague impressions, about human passions or mental states. Fictions take in charge psychological paintings, for which truth is not anymore factual but deals with th e inner life of a person. It appears to be really specific to fictions because this is precisely a fictional treatment which can develop that sort of thought. For example, Sade claims that the novel depict s "the truth of hum an being when leaving his mask", and latter judges this picture as " $m$ uch more interesting and at the sam e time truer" (1800:54). This intentional truth is theref ore only possible through the narrative dynam ic dimension of fictions; and so, the characteriza tion - which here means both to specify and to create a character - involves the production of what R. Barthes calls the "truth of affects" (1978).

We might bring some reservations to the idea that these truths are literal; they are $\mathrm{m}$ ostly literal. But in the perspective we adopt at this point, we could also include the practice of some novelists to give the power of language to those who lacks it in the real world: angels, deads, trees, animals and so on. In this case, tr ue statements appear to be quite $m$ etaphorical. They are a form of intuitive understanding of wh at is beyond us, and therefore an attem pt to make sense.

All in all, the reason why $\mathrm{f}$ ictional treatment is desirable for it is the nature of objects in question: meanings of events as they are e xperienced, perceived or projected in $m$ any ways, human heart, inanim ate entities, dream s and subconscious thoughts, as well as life itself, meanings of life and reasons to accept the existence we have, cannot be the rei of the truth conception as adequatio. However, their occurrence within a fictional discourse can have as a result to be close to som ething true, for they are m erged into the global tendency of understanding. Being true means here that we judge it as likely to what we really feel or think, how we act in our life, or how things appear to signify for us. But this truth is not reducible to clear and exact form ulas; they are vaguely referential truths, $m$ ixed with their narrative expression.

Because fictions are oriented to a $\mathrm{m}$ oral axiological interrogation, as T. Pavel (2003), J. Bouveresse (2008), M. Nussbaum (1995) and many others claim, then it seem s that we must modify and extend the concept of truth to give an account of it. Like we formerly said, there is no single valid interpretations of hum an attitudes, no scientific truths about the relations between human beings, or about one's right pos ition in the world. We do not know what true fixed principles we would have to follow in order to lead a good life! Nevertheless, because fictions are indispensable to clear up our $\mathrm{m}$ ind about this kind of deep existential questions, one can think that they say something true about it.

In this perspective, J. Bouveresse consider $\mathrm{s}$ that a novel fulfils this function when it develops a "situation of problem" in the m ost likely, plausible and relevant way (2008: 49). 
This likeness is next to the idea of the

"truth of a person", and it goes through the representation of his or her entire story, as Eng lish moral realists have tried to do. Therefore we follow D. Rozakis when he asserts that fictions, by m eans of reconstitutions and redefinitions endlessly iterated about the " possible content of an entire life" (2009: 78), propose different interpretations of hum an behaviors and reasons why we act such and such. Truths of fictions are of an herm eneutical kind, and consequently neither elim inable nor definitive.

\subsection{Irreducible and specific truths: four features}

The very specif ic kind of fictional truth is quite global and intuitive, and rather of a conceptual order - we follow here Bouveresse's claim (2008). It is hard to isolate what is true within a fictional story, because it appears to us as a fluid whole, and not stricto sensu expressed by a propositional form . So, we could say that truths from fictions deal with "monstration" rather than diction, even if it seem s paradoxical at first blush for the case of novels. But it $\mathrm{m}$ eans what $\mathrm{W}$ ittgenstein calls to mind when claim ing although in another context that what can not be said, can still be shown (1921: 6.522): in a way, what is true in the fiction cannot be reduced to a few words, but passes through lines without clearly standing into some linguistic close form ulas. We will now present four feat ures which draw the specificity of the concept of fictional truth.

(i) Links to falsehood and game. Of course, it seem s to be contradictory that being true depends in this situation of what is literally false. But it actually $m$ eans that the way how truths come to light depends on the illusionary dimension of stories. As J. M. Schaef fer (2008) outlines, the particular $\mathrm{m}$ odes of reception and $\mathrm{m}$ ental processes which give us an access to fictional universes are im mersion and, especially, simulation; they both determ ine which characteristic aspects fictional truths do possess.

So, illusion is indispensable to $\mathrm{f}$ iction which is indispensable to elaborate interpretative truths. The pretense dimension partly defines so me properties of fictional truths. W e have to act as if it was literally true, and then we $m$ ight be able to understand how it can be true as well about the world, in an analogical and intentional way. W e have to invent stories and characters in order to create an appropriate fr ame for some true statements which cannot be expressed otherwise.

This feature is moreover close to the ironic and playful dimension of fictional truths. In fact, many authors do enjoy the freedom to cloud the supposedly unbridgeable boundaries between what is true and what is false, in the very sense of what is real and wh at in fictional - we can for example look at som e prefaces by Montes quieu, Laclos or Rousseau (in Montalbetti 2001). Like the strange and soft way of expressing true things in fiction, fictional truths themselves seem to display an ironic nature.

(ii) Links to the questioning form. This is mostly due to the incompleteness of fictions and their spirit of complexity. Then truths can be characterized as being unfinished broken up intuitions with an evasive and changing dim ension. They appears to be problem atic and not checkable, undeterminable and som etimes paradoxical. Worse, they do not always follow logical rules when compared to one another. In this perspective, they can be considered as not systematic and quite provisory.

But then, are we really allowed to speak of truths? Yes we are, $f$ or the intentional aspect of language, as we already showed, do not answer to the sam e requirements than the use of descriptive or theoretical discourse. In the case of fiction, there is no unicity of significations, and novels have actually to respect the possibility of different interpretations about the world. For these reasons, it is im portant to outline the plural form of the term, ie. 
truths, for it would be erroneous to assert the exis tence of one Truth of fiction. Furtherm ore, novelists create some sort of unknown truths and it is not rare that many of them confess they do not know themselves at which kind of interpretations they will end up: truths from fictions are not conclusions implied by stated well-formed premises.

(iii) Links to words. The concept of fictional truths is more precisely inseparable to a linguistic work. ${ }^{28}$ It means that when we read a novel, we can pick up som e narrative truths, i.e. developed within a narrative schem e, but we can also discover truths which depend on words themselves, like analogical or $m$ etaphorical truths. This verbal dim ension is $m$ aybe close to our natural tendency for telling stories in order to make sense - this anthropological aspect of fictions has been studied for exam ple by J. Molino \& R. Lafhail-Molino (2003): the intentional use of language allows us to form ulate different significant hypothesis about some ordinary situations. Words, in that case, are useful to make a "situation of problem " clearer and apt to be cognitively controlled.

Novels sometimes allow a sort of external "typification" of som e names or narrative sequences; the reader will isolate them and then possibly apply it to real phenom enon or individuals. For exam ple, we have in $\mathrm{m}$ ind Peter Pan's type which analogically apply to someone who refuses to grow up, the bovarysm, next to Don Quixote's model, characterizing someone who confuses dreams or fictions with reality, or even the mental process illustrated by Proust's madeleine. Similarly, Balzacian "types" shed light on human behaviors. ${ }^{29}$ Fictions are used for real data being named, a way for the formers to pretend to a kind of truth. W hich one? Something like what N. Frye defines as "allegorical incidences" (1957).

Truths from fictions are intrinsically linked to words, for the reason that they express som e real features, by instance, em otions, for which "we do not have words at our disposal before reading a novel" (see Rozakis 2009: 117). Alike De scombes' idea of a possible expansion of our vocabulary by $m$ eans of fictional language, we $m$ ight claim that, when there is no adequate term to correctly and directly describe the nature of some human attitudes, then this is the function of a developed plot to give us the ability to understand what is involved. Take a look at, for example, Alexis' long letter in M. Yourcenar's short story, Alexis ou le Traité du vain combat (1927), who needs so $m$ any pages to barely $m$ anage to explain to his wife the failure of their $\mathrm{m}$ arriage. So novels do not only attempt to name moral and psychological motivations we could actually realize; they esp ecially try to "forge subtler languages" than ordinary one, and truths they carry on are then in straight connection with them.

(iv) Links to the possible. The fourth feature is certainly the most important one, because it actually overhangs the three others. Let's say now that the very specificity of truths fictions express is linked to the modal and deontic notion of possibility. Truths have to be considered as dealing with (1) ontological possibilities and (2) interpretative possibilities.

(1) On the one hand, novels seem to offer some forms of what is possible without having ever been realized. This is the case of utopias and thought experiences of which $\mathrm{R}$. Musil's novel is a paradigmatical picture. In this perspective, truths concern what does not yet happen, what could happen, what will maybe happen, that is what does not actually exist. This is why we bring nearer the concept of verisimilitude which means, in a way, what is possibly true in the real world, and really true in a possi ble fictional universe. This kind of truth is not

\footnotetext{
${ }^{28}$ Obviously, this point concerns more particularly the case of novel; movies answer to another kind of medium specificity. In general, fictional truths are linked to the form which expresses them - straight connection between form and content.

${ }^{29}$ We agree with J. Pouillon (1946: 94) who notices that "the type is what makes us understand something, rather than what is understood. [...] We see the real world through Balzac's eyes, we begin to find Balzacian characters everywhere".
} 
eliminable because it formulates possibilities which have never been instantiated. They com e from the prospective dim ension of fictions, inventing and imagining human possibilities of existence. According to J. M. Schaeffer, ficti on is therefore a "virtual exemplification of a possible being-in-the-world" (2008: 80).

Modal possibilities are close to the sam e but deontic notion $\mathrm{f}$ or both of them appear as an attempt to improve our moral thoughts and choices; the question is how to attain a good life. Following J. Bouveresse, the very object of novelis $t$ investigation is precisely this sort of practical truth. And once again, he says that the understanding from fictions is not at all "similar to knowledge of theoretical propositional science, for it is directly relative to the question of how we can or should live" (2008: 63).

(2) On the other hand, novels are deali ng with many possibilities of m eanings about what there is. Possible interpretations and po ssible world-conceptions express this $\mathrm{m}$ odal hermeneutical kind of truth. It is really clos e to Putnam's idea (1978) according to which the novel teaches us "to see the world as it looks lik e for someone who is sure this hypothesis is valid". Novels do then propose som ething like an hypothesis at first tim e, which they assume and develop through the story and which they m odify in accordance with the transform ations of characters.

Putnam asserts that novels permit us to be conscious of a new interpretation of facts and that it builds up a kind of true knowledge: "this is the knowledge of a possibility, he wrote. This is a conceptual knowledge' (1978), due to the writer's intuition - we should precise it is the conjunction of the writer's intuition and the reader's reception. But Putnam has a problem: an intuition is not really a knowledge, because know ledge must be based on a scientifically checked verification. Then novels would not be allowed to express som e truths, as it is impossible to scientifically know if it is true.

This kind of problem leads us to prefer another definition of what Putnam calls a "knowledge"; in our perspective, what he is cl aiming is correct, but only if we translate "the knowledge of a possibility" from its theoretical sense to its interpretative one as an understanding. The reason is that the intentiona 1 use of fictional language gives us an apprehension of life's signification, which is s till not apt to be confirm ed in any ways by facts. ${ }^{30}$

So truths of fictions are from a global level. They concern real hum an possibilities as well as possibilities of various interpretations. Both of them are quite inf inite and then im ply impossibilities of reduction. By this way, we preserve the applicability of fictional truths but without assuming a directly referential relation to reality. Here, being true does not $m$ ean that life is accurately represented within the fictiona 1 frame but rather that, as M. Backtine said, "life itself is able to enter the novel" (1978). Th e truth criteria would then be form ulated as follow: does the novel remain outside life and beside reality, this reality that it is supposed to take into consideration? ${ }^{31}$

\section{Additional remarks}

What really accounts for now is to accept the idea that fictions, because they are practically indispensable, do say something true about human beings and the world in which we live and act, think and feel, something true about its meaning and the multiple interpretations we may

\footnotetext{
${ }^{30}$ Fictions can also be considered as improving our modal faculties, being a way to experiment our modal judgments about what is possible and what seem to be impossible, in such and such situation.

${ }^{31}$ See also V. Woolf (1927).
} 
propose. All of it depends on an intentional use of language which is undoubtedly different from a descriptive use.

One obvious benefit of this conception is that the question of truth in fiction is given as independent from the question of the existe nce of fictional entities. W e do not suppose anymore that this kind of truth fictions e xpress is relative to the correspondence schem e. Truths are implied by their indispensable role, and not by a (necessarily failing) reference to empirically real facts. Therefore, nove list understanding for exam ple does not only concern what exists, but rather what could possibly exist if such and such, in such and such situation, according to such and such $\mathrm{m}$ odalities, and it concerns also the possible $\mathrm{m}$ eanings we could give to what exists. Incidentally, our concepti on implies that fictions which are useless - in the sense where they would not provide any new ability to their readers, like pulp literature are definitely not true.

A requirement as well as an implication of our proposal is that we can not anym ore strictly isolate fictional worlds from the actual one. As soon as we claim that fictions are useful to understand real phenomenon, we are committed to the approval of a straight contact between them. We will however precise that $\mathrm{f}$ ictional worlds do not superimpose possible worlds, for it may be the case of impossible fictional universes - like, by instance, in $\mathrm{f}$ antastic literature. Possible worlds do the job of conceptually joining fictional and real worlds, without involving any kind of equivalency.

We will end up to the debate about storytelling practices (hereafter ST; see Ch. Salm on 2007). The reason is that the necessity to disti nguish ST from novelist practices can be used for an argum ent in favor of the porosity betw een fictional and real world. Firstly, we can observe that in both cases there is a sim ilar fictional discourse, but with different functions. ST gives a full power to the "termites of reduction" until they manage to impose to people one single interpretation of the story. According to what we form erly claimed, this is a counter natural process for fictions, for their very specificity is to be multi-interpretable. The spirit of complexity vanishes into biased simplifications.

Secondly, the joint between fiction and reality is also different. ST denies what is real in order to create another chosen reality, deliberately misleading or at least due to one's own free will for instrumental ends. ST consciously trie s to cut of the connection between the wrong fallacious representation they extract from fictions and the true reality, substituting the former for the latter. In order to differentiate these two uses, we then need to admit that there actually is an outer reality which $\mathrm{m}$ akes true $\mathrm{m}$ any fictional statements and interpretations. And so novels are not separated from the world. Fictions are helpful for us to understand som e real irreducible aspects of reality, without choosing them and without corrupting it.

\section{Conclusion}

Roughly said, Frege, Russell and Quine reject ed fictions as being non-serious, thus uninterested by truth. However fictions play a cen tral and particular role in our hum an lives: this is the $\mathrm{m}$ ain reason why we cannot be satis fied with such approaches. W e argued that fictional narrations should not be considered as descriptive: what one can learn from them irreducibly is nothing but ways of interpreting others and the world. So fictional narrations should not be processed like descriptive or theoretical discourse. However, theoretical discourse is the target of Quine's criterion of ontological com mitment, as well as that of Quine-Putnam's indispensability argument. 
We proposed to clearly detach two parts within the indispensability argum ent: (i) the implication from indispensability to truth, and (ii) the implication from truth to ontology. The second part actually is Quine's ontological criteri on. If the argument is to be transposed from theoretical to fictional discourse, then one can retain (i) but should give up (ii).

The implication from truth to ontology (ii) is specific to theoretical discourse, if not to firstorder formalized theories. The developm ent of NL sem antics since the 1970s reveals how insufficient hence inadequate is first-order logic to account for $\mathrm{m}$ any linguistic phenomena. Fine-grained analyses, especially those provi ded since the dynam ic turn in NL sem antics, emphasized the need of explanations of how peopl e interpret discourse in context, rather than static descriptions of meanings of expressions in isolated eternal sentences. Doing such a task, semanticists promoted two-level theories, i.e. th e addition of a kind of "internal level" to the usual model-theoretic one. The way linguistic interpretation is handled is thus made relatively independent of the representative level, that is of the external connection between language and world. Obviously (ii) concerns the represen tative dimension of semantics, and not at all the procedural one. At the internal level, one can account for som e kind of truth of a discourse, with no relation to the world, hence with no ontological commitment.

Nevertheless, only a half of the way has been m ade. Such a truth is indeed a weak one: it is internal and cannot be considered as serious . Assuming (i), we argued that fiction, being indispensable, is true in a strong sense. It does not mean at all that fictional narrations have a descriptive dimension, i.e. that they describe the world in som e specific manner. The strong sense of truth comes from a connection to the world, but a connection that is strictly different from representation. As fictional narration is no description, the correspondence theory of truth is clearly out of place. W e used analys es by literary criticism and philosophy of art to account for the specificity of fictional truths. Trut $\mathrm{h}$ in fiction intervenes at a global level, and it is connected to m odality: because fictions offe $r$ many interpretations, their truth is that of the interpretative possibilities they let explore. In a way, this can be conceived of as in relative accordance with Lewis' and $m$ any philosophers' idea to account for the sem antic of fictions using possible world semantics.

\section{Acknowledgments}

We would like to thank Jacques Morizot and Roger Pouivet for their comments on an earlier version of this paper, and the editors of this volume for their invitation to contribute.

\section{References}

Asher, N., 1993: Reference to Abstract Objects in Discourse, Dordrecht, Kluwer.

Backhtine, M., 1978, Esthétique et théorie du roman, trad. D. Olivier, Gallimard, Paris.

Balzac, 1862, Avant-Propos à La Comédie humaine, Seuil, « L’intégrale », 1965.

Barthes, R., 1978, « Longtemps je me suis couché de bonne heure », in Le Bruissement de la langue,. Essais critiques $I V$, Seuil, « Points Essais », Paris.

Barwise, J., 1979, “On Branching Quantifiers in English”, Journal of Philosophical Logic 8, 47-80.

Baudelaire, C., 1857, « Notes sur Edgar Poe », in Euvres complètes, t.II, ed. Cl. Pichois, Gallimard, coll. « La Pléiade », 1976.

Beaver, D. I.: 1997, "Presupposition", in J. van B enthem \& A.t er Meulen (eds), Handbook of Logic and Language, Elsevier, Amsterdam, 939-1008.

Benjamin, W., 1936, « Le narrateur. Réflexions à propos de l'œuvre de Nicolas Leskov », in Ecrits français, Gallimard, Paris, 1991, pp.264-298.

Bouveresse, J., 2008, La connaissance de l'écrivain. Sur la littérature, la vérité et la vie, Agone, Marseille.

Calvino, I., 1985, Interview by P. Fournel, in Magazine Littéraire n459, dec. 2006, pp.78-79. 
Carnap, R., 1950, “Empiricism, Semantics and Ontology”, Revue Internationale de Philosophie 4, 20-40.

Colyvan, M., 2008, "Indispensability Arguments in Philosophy of Mathem atics", Stanford Encyclopedia of Philosophy.

Cooper, R., R. Crouch, J. van Ei jck, C. Fox, J. van Ge nabith, J. Jaspers, H. Kam p, M. Pinkal, M. Poesio, S. Pulman, Espen VestreCooper, 1994: Describing the Approaches, FraCaS Deliverable D8, December 1994.

Darsel, S. \& Poui vet, R., 2008, Ce que l'art nous apprend. Les valeurs cognitives dans les arts , Presses Universitaires de Rennes.

Dennett, D. C., 1987, The Intentional Stance, The MIT Press, Cambridge, Mass.

Descombes, V., 1987, Proust, Philosophie du roman, Les Editions de Minuit, Paris.

Descombes, V., 1995, La Denrée mentale, Les Editions de Minuit, Paris.

Donnellan, K. S., 1966, "Reference and Definite Description”, The Philosophical Review 77, 281-304.

Evans, G., 1982, The Varieties of Reference, Oxford University Press, New York.

Fraisse, E. \& Mouralis, B., 2001, Questions générales de littérature, Seuil, Paris.

Frye, N., 1957, Anatomy of Criticism: Four Essays, Princeton University Press.

Furetière, 1666, Le roman bourgeois, ed. M. Roy-Garibal, GF-Flammarion, 2001.

Genette, G., 1969, Figures II, Seuil, Paris.

Genette, G., 1991, Fiction et diction, Seuil, "Poétique”, Paris.

Gochet, P., 2010, La t héorie de l'objet de Meinong à la lumière de la logique actuelle, in P. Bour et al. (eds.), Construction. (to appear)

Goodman, N., 1978, Ways of Worldmaking, Hackett Publishing Company.

Groenendijk, J. \& M. Stokhof, 1991, “Dynamic Predicate Logic”, Linguistics and Philosophy 14, 39-100.

Groenendijk, J. \& M. Stokhf: 1999, “Meaning in Motion”, in K. von Heusinger and U. Egli (eds.), Reference and Anaphoric Relations, Kluwer, Dordrecht, 47-76.

Hintikka, J.: 1988, “On the Development of the model-theoretic viewpoint in logical theory”, Synthese 77, 1-36.

Hintikka, J., 1997, “No Scope For Scope?”, Linguistics and Philosophy 20, 515-544.

Hintikka, J. \& G. Sandu: 1997, “Gam e-Theoretical Semantics”, in J. van B enthem \& A. t er Meulen (eds), Handbook of Logic and Language, Elsevier, Amsterdam, 361-410.

Hofweber Th., 2000, "Quantification and Non-Existent Objects", in A. Everett \& Th. Hofweber (eds.), Empty Names, Fiction and the Puzzles of Non-Existence, CSLI Publications, Stanford, 249-273.

Hugo, V., 1862, Les Misérables, ed. R. Journet, GF-Flammarion, 1967, t.III, pp.6-10.

Kamp, H., 1981, “A theory of truth and semantic representation”, in Stokhof, J., Groenendijk, T., Janssen (Eds), Formal methods in the study of language, Matematisch Centrum, Amsterdam, pp 277-322.

Kamp, H., \& U. Reyle. 1993. From Discourse To Logic, Kluwer Academic Publishers, Dordrecht.

Kripke, S. A., 1976, "Is There a Problem about Substitutional Quantification?", in G. Evans \& J. M cDowell (eds.), : Truth and Meaning, Clarendon Press, Oxford, 325-419.

Kripke, S. A., 1977, “Speaker's Re ference and Semantic Reference”, in P.A. French, T.E. Uehling Jr., \& H.K. Wettstein (eds), Studies in the Philosophy of Language, Midwest Studies in Philosophy, no. 2, Uni versity of Minnesota Press, Mineapolis.

Kundera, M., 1986, L’art du roman, Gallimard, Paris; repr. 1995, « Folio » Gallimard, Paris.

Lamarque, P. \& Olsen, S.H., 1994, Truth, Fiction and Literature, Clarendon Press, Oxford.

Lambert, K., 2003, Free Logic. Selected Essays, Cambridge, Cambridge University Press.

Macdonald, M., 1954, “The language of fiction”, in Proceedings of the Aristotelian Society, suppl. vol. 27.

Menoud, L., 2005, Qu'est-ce que la fiction?, Vrin, Paris.

Molino, J. \& R afhail-Molino, R., 2003, Homo Fabulator. Théorie et analyse du réci t, Léméac/Actes Sud, Montréal.

Montalbetti, Ch., 2001, La Fiction, Flammarion, Paris. 
Morizot, J., 2008, « Enjeu cognitif et/ou théorie cognitive », in Darsel, S. \& Pouivet, R., 2008, Ce que l'art nous apprend. Les valeurs cognitives dans les arts, Presses Universitaires de Rennes, pp.49-66.

Nussbaum, M., 1995, Poetic Justice. The Literary Imagination and Public Life, Beacon Press, Boston.

Pavel, T., 2003, La Pensée du roman, Gallimard, Paris.

Peregrin, J., 2000, "Reference and Inference: The C ase of Anaphora", in K. von Heusinger \& U. Egli (eds), Reference and Anaphoric Relations, Kluwer, Dordrecht, 269-286.

Piégay-Gros, N., 2005, Le Roman, Flammarion, Paris.

Pouillon, J., 1946), Temps et roman, Gallimard, Paris.

Pouivet, R., 2008, "Est hétique modale", in S. Darsel et R. Pouivet, Ce que l'art nous apprend. Les val eurs cognitives dans les arts, Presses Universitaires de Rennes, pp.35-48.

Putnam, H., 1978, « Literature, Science and Reflection », in Meaning and the Moral Sciences, Routledge \& Kegan Paul, Londres-Henlay-Boston.

Putnam, H., 1979a, "What is Mathematical Truth", in Mathematics Matter and Method: Philosophical Papers, Volume 1, 2nd edition, Cambridge: Cambridge University Press, pp. 60-78.

Putnam, H., 1979b, "Philosophy of Logic", reprinted in Mathematics Matter and Method: Philosophical Papers, Volume 1, 2nd edition, Cambridge: Cambridge University Press, pp. 323-357.

Quine, W. V. O., 1948, “On What There Is", Review of Metaphysics 2. Repr. In From A Logical Point of View, Harper \& Row, New York, 1961, 1-19.

Quine, W. V. O., 1960, Word and Object, Cambridge Massachusetts, The M.I.T Press.

Quine, W.V., 1976, "Carnap and Logical Truth" reprinted in The Ways of Paradox and Other Essays, revised edition, Cambridge, MA: Harvard University Press, pp. 107-132.

Quine, W.V., 1981, Theories and Things, Cambridge, MA: Harvard University Press, pp. 1-23, 148-155.

Rahman, Sh., 2009: "Fiction, Creation and Fictionality. An Overview", Manuscript.

Recanati, F., 2000, Oratio Obliqua, Oratio Recta. An Essay on Met arepresentation, MIT Press, Cam bridge, Mass.

Reimer, M., 1998, “Quantification and Context”, Linguistics and Philosophy 21, 96-115.

Reinhart, T., 1997, “Quant ifier Scope. How Labor is Divided Between QR and Choice Functions”, Linguistics and Philosophy 20, 335-297.

Rivière, J., 1913, “Le rom an d'aventure”, in Etudes 1909-1923. L'œuvre critique de Jacques Rivière à la Nouvelle Revue Française, Gallimard, Paris, 1999, p.344-347.

Rozakis, D., 2009, Qu'est-ce qu'un roman?, Vrin, Paris.

Russell, B., 1905 : “On Denoting”, Mind 14, 479-93.

Sade, 1800, Idée sur les romans, Ducros, 1970.

Salmon, Ch., 2007, Storytelling. La Machine à fabriquer des histoires et à formater les esprits, La Découverte, coll. « Cahiers libres », Paris.

Schaeffer, J. M., 2008, « Quelles valeurs cognitives pour quels arts ? », in S. Darsel et R. Pouivet, Ce que l'art nous apprend. Les valeurs cognitives dans les arts, Presses Universitaires de Rennes, pp.67-81.

Schlenker, Ph., 2006: "Scopal Independence: A Note on Branching \& Island-Escaping Readings of Indefinites \& Disjunctions", Journal of Semantics 23 (3), 281-314.

Strawson, P. F., 1950, “On Referring”, Mind 59, 320-344.

Van Heijenoort, J., 1967, “Logic as Language and Logic as Calculus”, Synthese 17, 324-30.

Winter, Y., 2004: "Functional Quantification”, Research on Language and Computation 2, 331-363.

Wittgenstein, L., 1921, Tractatus Logico-Philosophicus ; trad. fr. P. Klossowski, Gallimard, Paris, 1961.

Woolf, V., 1927, L'art du roman, trad. R. Celli, Seuil, Paris, 1963.

Zalta, E. N.: 1984, "Referring to Fictional Characters”. (Unpublished manuscript). 


\section{Inventory of quoted novels.}

Barnes, J., Talking it o ver (1991); Broch, H., Les Somnambules (1931-32); Calvino, I., Palomar (1985) ; Durrell, L., Le Quatuor d'Alexandrie (1957-60) ; Gary, R., Les Racines du ciel (1956) ; Kristof, A., Le Grand Cahier (1986), La preuve (1988), Le Troisième mensonge (1991); Musil, R., L'Homme sans qualités (1930-33) ; Strindberg, S., La Fabrique des rêves (2009) ; Yourcenar, M., Alexis ou le Traité du vain combat (1927).

Balzac, H. de, le cycle de La Comédie humaine ; Zola, E., le cycle des Rougon-Macquart.

About the question of barbarity: Coetzee, J. M., En attendant les barbares (1980); Eschyle, Les Perses (472 av. J.C.) ; Flaubert, G., Salammbô (1862).

About the theme of the stupidity : Grass, G., Le Tambour (1960); Singer, I. B., Gimpel le naïf(1956).

But also: Austen, J.; Beckett ; Berhard, T. ; Boileau ; Borges ; DeLillo, D. ; Dostoïevski ; James, H. ; Jelinek, E. ; Kafka; La Fontaine ; Lucrèce ; Proust ; Senges, P... 